\title{
Identifikasi Zat Pewarna Makanan Rhodamin B Pada Jajanan Mie Lidi Di Sekolah Kecamatan Ajibarang Kabupeten Banyumas 2020
}

\author{
Eko Hidayaturrohman Khumaeni ${ }^{1}$, Kristian Ubanayo ${ }^{2,}$ Yulia Maulidatul Karomah $^{3}$ \\ ${ }^{123}$ Program Studi D3 ANAFARMA, STIKes Ibnu Sina Ajibarang, Indonesia \\ e-mail: ${ }^{1}$ ekohidayatkh@stikes-ibnusina.ac.id, ${ }^{2}$ kristianubanayo@stikes-ibnusina.ac.id, \\ yulia.mahasiswa@stikes-ibnusina.ac.id
}

\begin{abstract}
ABSTRAK
Mie lidi merupakan salah satu makanan ringan yang dijual dengan warna menarik, harganya murah sehingga digemari oleh anak-anak. Pewarna sintetis yang sering digunakan adalah rhodamin B. Tujuan penelitian: untuk mengetahui cara memisahkan zat rhodamin B dalam mie lidi, metode analisis yang tepat untuk menguji zat rhodamin B dalam mie lidi dan kadar rhodamin B yang terkandung dalam sampel mie lidi. Sampel mie lidi diambil di tiga sekolah kecamatan Ajibarang. Metode penelitian deskriptif dengan melakukan observasi. Variabel Penelitian variabel bebas, variabel terikat, variabel terkendali. Hasil uji KLT sampel A merah gelap Rf 0,85; sampel B kuning keruh Rf 0,69; sampel C merah terang Rf 0,77; standar Rhodamin merah muda Rf 0,78. Artinya sampel C positif karena nilai $R f$ sampel $=$ Rf standar Rhodamin $B$.

Hasil uji SPEKTRO UV-VIS absorbansi Ekstrak sampel diperoleh 0,175 pada panjang gelombang 555 nm. Berdasarkan nilai absorbansi yang diperoleh dapat diketahui bahwa konsentrasi sampel sebesar0,1840 ppm. kesimpulan penelitian menunjukkan bahwa terdapat Rhodamin B dalam sampel yang kuantitasnya sangat kecil hingga hasil dari perhitungan kadar menunjukkan nilai minus (-). Hal ini dikarenakan ekstrak sampel yang diperoleh memiliki kepekatan yang sangat rendah sehingga nilai absorbansinya (y) lebih kecil dari nilai konstanta (a).
\end{abstract}

Kata kunci : Mie Lidi, Rhodamin B, Spektro UV-VIS

\begin{abstract}
Mie Lidi is one of the snacks sold in attractive colors, low price so favored by children. The synthetic dyes that are often used are Rhodamin B. The purpose of the analisys to know how to separate rhodamin $B$ substances in Mie Lidi, the right method of analysis to test Rhodamin B substances in noodles and levels of Rhodamin B contained in the sample noodles Lidi. Samples of noodles were taken in the three schools of Ajibarang subdistrict. A descriptive research method by observing. Variable research free variables, variable bound, variables controlled. Sample KLT test result dark red Rf 0.85; Sample B yellow murky Rf 0.69; Sample C bright red Rf 0.77; Standard Rhodamin Pink Rf0.78. It means a positive $C$ sample due to the sample $R f$ value $=R f$ Standard Rhodamin B.

SPECTRO UV-VIS absorption test result extract samples obtained 0.175 at a wavelength of $555 \mathrm{~nm}$. According to the Absorbancy value obtained can be known that the sample concentration of-0.1840 ppm. The research conclusion shows that there is Rhodamin B in a sample that is very small in quantity until the result of the rate calculation indicates a minus (-) value. This is because extracts of the samples obtained have very low concentrations so that the absorption value (y) is smaller than the value of constants (a).
\end{abstract}

Kata kunci : Mie Lidi, Rhodamin B, Spektro UV-VIS

\section{PENDAHULUAN}

Kecamatan Ajibarang merupakan daerah yang jumlah penduduknya cukup banyak, serta banyak terdapat sekolah yang tentunya menjual aneka macam jajanan, salah satunya adalah mie lidi. Mie lidi merupakan salah satu jenis jajanan yang biasanya dijual dengan rasa dan warna yang menarik, harganya relatif murah sehingga digemari oleh anak-anak. Hal ini dimanfaatkan oleh produsen mie lidi untuk mendapatkan keuntungan yang lebih besar dengan menggunakan zat warna sintetis karena harganya yang lebih murah dan warnanya yang lebih menarik. 
Pewarna sintetis yang sering digunakan salah satunya adalah rhodamin B. Rhodamin B merupakan zat warna sintetik umum yang digunakan sebagai pewarna tekstil dan zat warna tambahan yang dilarang penggunaannya dalam produk-produk pangan. Rhodamin B bersifat karsinogenik sehingga dalam penggunaan jangka panjang dapat menyebabkan kanker[1].

Rhodamin B, pemerian hablur hijau atau serbuk ungu kemerahan. Kelarutan sangat mudah larut dalam air, menghasilkan larutan merah kebiruan dan berfluorosensi kuat jika diencerkan. Sangat mudah larut dalam etanol, sukar larut dalam asam encer dan dalam larutan alkali. Larut dalam asam kuat, membentuk senyawa dengan kompleks antimoni berwarna merah muda yang larut dalam isopropil eter[2].

Penelitian yang dilakukan oleh [3] metode yang cocok digunakan untuk analisis rhodamin B salah satumya adalah dengan Kromatografi Lapis Tipis (KLT). Kromatografi merupakan metode pemisahan multi tahap dimana komponen suatu sampel didistribusikan antara dua fase, yaitu fase diam dan fase gerak. Pada kromatografi lapis tipis fase diam berupa lapisan tipis, kering merata, terbuat dari bahan serbuk halus dilapiskan secara akurat pada suatu kaca, plastik atau lempeng aluminium (umumnya semua disebut lempeng). Fase diam dari lempeng kromatografi lapis tipis (KLT) mempunyai ukuran partikel rata-rata $10-15 \mu \mathrm{m}$, dan KLT mempunyai ukuran partikel rata-rata $5 \mu \mathrm{m}$. Lempeng komersial dengan zona preadsorbent dapat digunakan apabila spesifikasinya sesuai dengan monografi. Sampel ditotolkan pada daerah preadsorbent dikembangkan dalam pita pendek yang tajam pada interface preadsorbentsorbent. Pemisahan dicapai berdasarkan adsorpsi, partisi, atau kombinasi dari keduanya, tergantung pada jenis partikel dari fase diamnya[4].

Analisis kandungan rhodamin B pada sampel mie lidi selanjutnya menggunakan Metode Spektrofotometri. Spektrofotometri merupakan pengukuran emisi cahaya dari suatu zat kimia selama diberi paparan ultra violet, cahaya tampak atau radiasi elektromagnetik lainnya. Pada umumnya cahaya yang diemisikan oleh larutan yang berfluoresensi mempunyai intensitas maksimum pada panjang gelombang yang biasanya 20 - $30 \mathrm{~nm}$ lebih panjang dari panjang gelombang radiasi eksitasi[2].

Sebagian besar bahan farmasi pengukuran spektrum dalam daerah ultra violet dan cahaya tampak dapat dilakukan dengan ketelitian dan kepekaan yang lebih baik daripada dalam daerah inframerah dekat dan inframerah[5]. Apabila larutan diamati dalam sel $1 \mathrm{~cm}$ dengan kadar lebih kurang $10 \mu \mathrm{m}$ per ml contoh, sering menghasilkan serapan sebesar 0,2 - 0,8 di daerah ultra violet atau cahaya tampak. Di daerah inframerah dan inframerah dekat diperlukan kadar berturut-turut sebesar 1 - $10 \mathrm{mg}$ per $\mathrm{ml}$ dan sampai $100 \mathrm{mg}$ per ml, untuk menghasilkan serapan yang memadai, untuk daerah spektrum ini biasanya dipakai sel dengan panjang 0,01 - $3 \mathrm{~mm}[6]$.

Berdasarkan permasalahan diatas, masih banyaknya produk mie lidi yang beredar dengan warna yang mencolok. Hal ini mendorong peneliti untuk melakukan analisis kandungan rhodamin B dalam sampel mie lidi yang beredar di wilayah Ajibarang wetan dengan harapan kedepannya tidak ada produsen mie lidi yang menambahkan zat berbahaya ke dalam produk olahannya.

\section{A. Jenis Penelitian}

\section{METODE PENELITIAN}

Metode penelitian ini merupakan deskriptif laboratorium yaitu dengan melakukan observasi pada mie lidi yang dicurigai mengandung rhodamin $\mathrm{B}$ dan dilakukan dengan melakukan analisis sampel di laboratorium.

\section{B. Variabel Penelitian}

Variabel bebas

Variabel terikat

: mie lidi yang di curigai mengandung Rhodamin B

: nilai Rf pada uji KLT

Variabel terkendali : jenis metode yang di gunakan adalah KLT dengan menggunakan silika gel 254 dan spektrofoometri UV.

\section{Alat dan Bahan}


online)

Tabel 1. Alat dan Bahan

\begin{tabular}{|c|c|}
\hline Alat & Bahan \\
\hline Erlenmeyer & Mie lidi berwarna merah \\
\hline Benang wol & lempeng silica gel \\
\hline Chamber & Akuades \\
\hline Kertas saring (Whatman NO. 1) & etanol $70 \%$ \\
\hline Spektrofotometer UV-Vis & larutan asam klorida \\
\hline Batang pengaduk & larutan ammonia \\
\hline Pipet & n-butanol \\
\hline Gelas ukur & etil asetat \\
\hline \multicolumn{2}{|l|}{ Gelas kimia } \\
\hline \multicolumn{2}{|l|}{ Labu takar } \\
\hline Timbangan Analitik & \\
\hline Corong pisah & \\
\hline
\end{tabular}

\section{HASIL DAN PEMBAHASAN}

\section{A. Hasil}

a) Uji Kualitatif dengan Metode Kromatgrafi Lapis Tipis

Tabel I. Hasil Uji Kualitatif dengan Metode Kromatgrafi Lapis Tipis

\begin{tabular}{ccc}
\hline Sampel & Warna & Nilai Rf \\
\hline Sampel A & Merah gelap & 0,85 \\
\hline Sampel B & Kuning keruh & 0,69 \\
\hline Sampel C & Merah terang & 0,77 \\
\hline Standar Rhodamin & Merah muda terang & 0,78 \\
\hline
\end{tabular}

Berdasarkan data diatas dapat diambil hasil berupa sampel $\mathrm{C}$ psitif mengandung pewarna rhodamin B karena nilai Rf mendekati nilai Rf standar rhodamin B.

\section{b) Uji Kuantitatif dengan Metode Spektrofometer Vissible}

Berikut adalah data yang didapat dari uji kuantitatif dengan metode spektrovotometer vissible pada panjang gelombang $554 \mathrm{~nm}$ :

a. Pembuatan Kurva Standar

- Pembuatan Larutan Baku Standar

$\mathrm{V} 1 \times \mathrm{N} 1=\mathrm{V} 1 \times \mathrm{N} 2$

$\mathrm{V} 1 \times 1000=100 \times 10$

$\mathrm{V} 1=1 \mathrm{ml} / 1,2 / 1,4 / 1,6 / 1,8$ sebanyak $100 \mathrm{ml}$

- Hasil pengukuran larutan baku standar rhodamin B

Tabel 2. Hasil Uji pengukuran larutan baku standar rhodamin

\begin{tabular}{c|cc}
\hline $\boldsymbol{N} \boldsymbol{O}$. & Standar Rhodamin $\boldsymbol{B}$ & Absorbansi \\
\hline 1 & $0,1 \mathrm{ppm}$ & 0,362 \\
\hline 2 & $0,2 \mathrm{ppm}$ & 0,391 \\
\hline 3 & $0,3 \mathrm{ppm}$ & 0,423 \\
\hline 4 & $0,4 \mathrm{ppm}$ & 0,456 \\
\hline 5 & $0,5 \mathrm{ppm}$ & 0,487 \\
\hline 6 & $0,6 \mathrm{ppm}$ & 0,525 \\
\hline
\end{tabular}




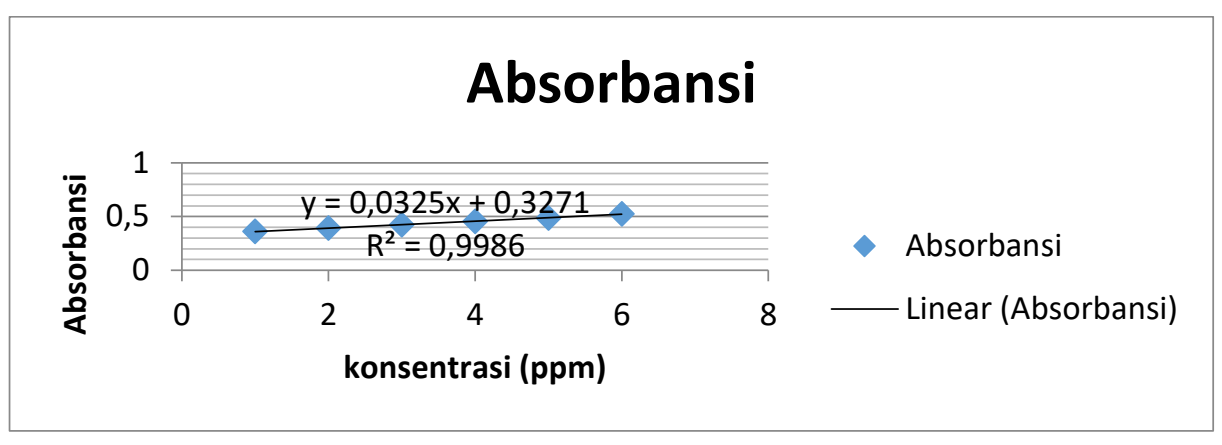

Gambar 1. Kurva Kalibrasi Larutan Baku Standar Rhodamin B

\section{B. Pembahasan}

Penelitian yang dilakukan kali ini bertujuan untuk menganalisis rhodamin B yang diduga terkandung dalam sampel mie lidi yang banyak beredar di pasaran. Analisis yang dilakukan dalam percbaan kali ini yaitu analisis kualitatif dan analisis kuantitatif, metde yang digunakan dalam analisis kualitatif yaitu metde Kromatografi Lapis Tipis dan untuk analisis kuantitatif menggunakan metode Spektrofotometri UV-Vis. Sampel yang digunakan merupakan sampel mie lidi yang beredar di sekitar sekolah di wilayah Ajibarang Wetan[7]. Analisis kandungan rhodamin b dilakukan karena rhodamin B dalam makanan perlu diawasi keberdaannya sebab rhodamin B merupakan pewarna sintesis yang biasa digunakan pada industri tekstil bukan industri makanan sehingga penggunaan rhdamin B dalam suatu sediaandilarang karena dapat menimbulkan dampak yang tidak diharapkan bagi kesehatan seperti gangguan ginjal, hati, dan kanker[8].

Rhodamin B adalah salah satu bahan pewarna sintesis makanan yang dilarang penggunaannya di Indonesia utamanya sejak 1985 melalui Peraturan Menteri Kesehatan. WHO secara resmi juga telah mengumumkan bahwa zat tersebut berbahaya karena kandungan logam berat dan sifat kimiawinya [9]. Di Eropa, zat ini telah lama dilarang karena digolongkan dalam kategori karsinogen yang dapat memicu kanker. Karena efek samping yang begitu besar, zat ini bahkan tidak hanya berbahaya jika dijadikan pewarna makanan, akan tetapi juga pada produk kosmetik. Bahkan, unsur berbahaya dalam rodhamin B tidak hanya terdapat dalam senyawa organiknya, akan tetapi juga senyawa anorganik ataupun ketika terkontaminasi oleh senyawa anorganik lainnya. Oleh karena itu, untuk mengetahui apakah rhodamin B masih banyak beredar di pasaran terutama pada makanan dengan warna yang mencolok seperti mie lidi, peneliti menguji mie lidi yang beredar di pasaran dengan menggunakan dua metode analisis[5].

Analisis pertama yang dilakukan adalah analisis kualitatif. Analisis kualitatif yang dilakukan ini berfungsi untuk mengidentifikasi keberadaan rhodamin B dalam sampel mie lidi. Metode yang digunakan dalam analisis secara kualitatif adalah metode Kromatgrafi Lapis Tipis yang merupakan salah satu teknik pemisahan senyawa dengan prinsip adsorpsi dan koefisien partisi[10]. KLT dilakukan karena pengujian menggunakan metode ini mudah dilakukan dan murah. Prinsip kromatografi lapis tipis yaitu perbedaan kepolaran "like disolve like" dimana pelarut yang bersifat plar akan berikatan dengan senyawa yang bersifat polar juga dan sebaliknya, semakin dekat kepolaran antara senyaa dengan eluent maka senyawa akan semakin terbawa oleh fase gerak tersebut[11].

Tahap pertama yang dilakukan adalah preparasi larutan sampel. Preparasi sampel dilakukan untuk memperoleh larutan rhodamin B dalam sampel sehingga bisa dianalisis dengan KLT dimana sampel yang diuji harus berupa larutan. Preparasi sampel dilakukan dengan cara merendam sampel mie lidi yang akan diuji dengan larutan $2 \%$ amonia dalam $70 \%$ etanol dengan perbandingan 1:2 selama 1 malam. Hal ini bertujuan agar rhodamin B dalam sampel dapat larut semua. Larutan $2 \%$ amonia dalam $70 \%$ etanol dipilih dalam percobaan kali ini sebab ammonia merupakan pengikat sekaligus pelarut rhodamin B sehingga rhodamin B akan terambil sempurna dalam sampel yang akan dianalisis. Selanjutnya, larutan disaring dengan menggunakan kertas whatman NO. 1. Filtrat yang dihasilkan kemudian dipekatkan dengan cara pemanasan menggunakan hot plate. Residu hasil penguapan tersebut kemudian dilarutkan 
dengan larutan asam (10 $\mathrm{mL}$ air dan $5 \mathrm{~mL}$ asam asetat $10 \%)$ dengan tujuan untuk menstabilkan rhodamin B agar tidak berubah dari bentuk terionisasi menjadi bentuk netral[11].

Langkah selanjutnya yaitu memasukkan benang wol berukuran $15 \mathrm{~cm}$ dalam larutan kemudian didihkan selama 10 menit. Penggunaan benang wol dalam percobaan kali ini berfungsi untuk mengekstraksi rhodamin B dalam sampel yang telah menerima perlakuan, dengan bantuan asam asetat yang sebelumnya telah ditambahkan terlebih dahulu, sehingga dihasilkan warna benang wol yang berubah dari putih menjadi merah terang. Selain itu fungsi digunakannya benang wol adalah sebagai absorben warna mie lidi sedangkan asam asetat glasial berfungsi sebagai pemberi suasana asam dimana pada suasana ini rhodamin B akan tertarik oleh asam dan selanjutnya akan terabsorbsi oleh benang wol. Hal ini menandakan bahwa rhodamin B dalam larutan telah terikat pada benang wol. Namun, karena sampel uji KLT harus berupa larutan maka rhodamin dalam sampel perlu dilarutkan dengan menggunakan pelarutnya yaitu larutan $10 \%$ amonia dalam $70 \%$ etanol[12].

Hasil yang didapat berupa larutan berwarna merah terang yang mengidentifikasi bahwa dalam sampel mie lidi terdapat rhodamin B. Selanjutnya dilakukan penyiapan fasa diam dan fasa gerak dari sistem kromatografi lapis tipis ini. Fasa diam yang digunakan adalah plat alumunium. Plat tipis aluminium berfungsi sebagai fasa diam yang merupakan tempat berjalannya adsorbens sehingga proses migrasi analit oleh solventnya dapat berjalan, sedangkan fase gerak yang digunakan dalam percobaan kali ini adalah campuran n-butanol: etil asetat: amonia (10: 4:5) dengan total volume eluent yaitu $19 \mathrm{~mL}[11]$.

Eluen yang digunakan pada percobaan kali ini bersifat polar, dikarenakan etil asetat dan ammonia yang bersifat polar dan n-butanol yang bersifat semipolar. Pada etil asetat, adanya gugus karboksil menyebabkan sifatnya semakin polar namun dengan semakin panjangnya rantai karbon menyebabkan sifat polarnya semakin lemah sehingga menyebabkan etil asetat bersifat polar[13]. Lalu pada n-butanol, adanya gugus hidroksil membuat zat ini bersifat semi polar sedangkan pada ammonia, adanya gugus amino akan membuat ammonia bersifat polar. Penggunaan eluen yang bersifat polar ini berkaitan dengan sifat kebanyakan zat warna yang bersifat polar termasuk Rhodamin B, juga kemudahannya untuk dapat larut dalam alcohol dan amonia. Oleh karenanya digunakan eluen yang bersifat polar ini agar dapat mengelusi Rhodamin B dengan baik sebab Rhodamin B juga bersifat polar. Apabila digunakan eluen yang bersifat non polar seperti kloroform, maka Rhodamin B tidak akan terelusi. Selain itu, Eluent tersebut dipilih karena sifatnya lebih polar dari fase diamnya sehingga sampel yang polar tidak terikat kuat pada fase diamnya[13].

Eluent dipilih dengan kombinasi demikian karena dapat menghasilkan spot yang bagus, pemisahannya baik, dengan waktu pemisahannya juga yang tidak terlalu lama. Hal ini dikarenakan eluennya bersifat polar dan mudah menguap. Penggunaan eluent ini disesuaikan dengan sifar polar Rhodamin B karena memiliki gugus karboksil dengan pasangan elektron bebas dan gugus amina pada struktur molekulnya. Gugus karboksil dan amonia ini akan membentuk ikatan hidrogen intermolekular dengan pelarut polar sehingga mudah larut dalam pelarut polar. Oleh karena itu, digunakan campuran eluen polar agar dapat mengeluasi Rhodamin B dengan baik[14].

Absorben yang digunakan dalam metode KLT yaitu berupa silica gel (SiO2) yang tidak mengikat air sehingga noda yang tercipta lebih dapat focus dan tajam. Fase diam ini bersifat polar. Kepolaran ditentukan saat aktivasi plat (yaitu menggunakan pelarut yang bersifat semipolar yakni etil asetat). Sebelum mempartisi sampel, awalnya eluen terlebih dahulu dijenuhkan dengan tujuan untuk memastikan partikel fasa gerak terdistribusi merata pada seluruh bagian chamber sehingga proses pergerakan spot di atas fasa diam oleh fasa gerak berlangsung optimal, dengan kata lain penjenuhan digunakan untuk mengotimalkan naiknya eluent dan untuk menghindari hasil tailing pada pelat KLT selain itu penjenuhan yang dilakukan berfungsi untuk memudahkan saat eluasi sampe[10].

Selama proses penjenuhan, dilakukan persiapan fase diam yakni plat aluminium yang digunakan berukuran $10 \times 2,0 \mathrm{~cm}$. Plat tersebut diberi batas atas dan bawah masing-masing 0,5 dan $1 \mathrm{~cm}$. Fungsinya sebagai penanda jarak tempuh eluent. Batas bawah plat dibuat $1 \mathrm{~cm}$ agar tidak terendam oleh eluent. Jarak penotolan disesuaikan dengan lebar plat yang tersedia. Jarak penotolan tidak boleh terlalu berdekatan untuk menghindari bergabungnya spot masing-masing

Jurnal Ilmiah Jophus Vol. 2, No. 01, Agustus 2020 : 59-67 
larutan dan tidak boleh terlalu pekat untuk menghindari adanya tailing saat spot naik bersama fasa gerak. Penotolan dilakukan pada 4 titik, dimana 3 titik untuk ekstrak sampel dan 1 titik untuk larutan standar rhodamin $100 \mathrm{ppm}$. Larutan standar disini digunakan sebagai pembanding dan untuk mengetahui apakah terdapat ekstrak rhodamin B dalam sampel yang dianalisis melalui spot yang terdistribusi. Penotolan larutan baku dan sampel menggunakan pipa kapiler dengan tujuannya yaitu supaya penotolan kecil karena dalam KLT, penotolan yang baik diusahakan sekecil mungkin untuk menghindari pelebaran spot dan tidak menurunkan resolusi. Pelebaran spot dapat mengganggu nilai Rf karena memungkinkan terjadinya himpitan puncak[7].

Langkah selanjutnya, plat dimasukkan dengan hati-hati ke dalam chamber tertutup yang berisi fasa gerak (eluent) dengan posisi fasa gerak berada di bawah garis pada plat. Metode KLT yang digunakan dalam percobaan kali ini yaitu menggunakan metode ascending (naik). Fase gerak dibiarkan naik sampai hampir mendekati batas atas plat. Eluent dapat naik walaupun melawan gravitasi karena adanya afinitas. Pada proses naiknya fase gerak, komponenkomponen yang berbeda dalam campuran akan berjalan melewati fasa diam yang telah dijenuhkan sesuai dengan kepolarannya. Setelah mencapai batas atas, plat KLT diangkat dan dibiarkan kering diudara. Hal ini dilakukan berfungsi untuk menguapkan sisa pelarut yang masih terdapat pada plat untuk menjamin penguapan telah sempurna dan agar spot jelas terlihat[14].

Hasil KLT diamati di bawah sinar UV. Hasil yang didapat dari percobaan yang dilakukan kalini ini yaitu berupa 3 spot berfluoresensi yang masing - masingnya berwarna merah muda dan orange dengan jarak tempuh spot yang berdekatan. Namun, spot yang dianalisis adalah spot yang mirip dengan spot larutan standar Rhodamin b yakni merah muda terang. Berdasarkan hasil pengukuran, diperoleh jarak spot pada sampel $\mathrm{C}$ dengan batas bawah yaitu $5 \mathrm{~cm}$ sedangkan jarak tempuh pelarut yaitu $6,5 \mathrm{~cm}$. Rf yang didapat dari hasil pengamatan yaitu 0,77 sedangkan untuk Rf standar didapatkan sebesar 0.78. Nilai Rf yang diperoleh ini menyatakan ukuran daya pisah suatu zat dengan kromatografi planar (KLT), dimana jika nilai Rf-nya besar berarti daya pisah zat yang dilakukan solvent (eluenya) maksimum sedangkan jika nilai Rf-nya kecil berarti daya pisah zat yang dilakukan solvent (eluenya) minimum. Rf yang optimum yaitu berada pada rentang $0.5-0.8$. Pemisahan KLT, dapat dipengaruhi beberapa faktor-faktor seperti struktur kimia dari senyawa yang dipisahkan, sifat dari penyerap dan derajat aktifitasnya, tebal dan kerataan zat penyerap, kemurnian pelarut, derajat kejenuhan, teknik percobaan, jumlah cuplikan, temperatur, dan kesetimbangan[2].

Analisis kedua yang dilakukan dalam percobaan kali ini yaitu analisis kuantitatif rhodamin $\mathrm{B}$ dengan tujuan untuk mengetahui kadar rhodamin $\mathrm{b}$ dalam sampel mie lidi karena berdasakan uji kualitatif, sampel mengandung rhodamin B. Analisis kuantitatif dilakukan dengan menggunakan spektrofotometri UV-Vis. Metode spektrofotometri ini mempunyai prinsip yaitu hukum Lambert-Beer dimana hukum Lambert-Beer ini menyatakan bahwa konsentrasi suatu zat berbanding lurus dengan jumlah cahaya yang diabsorbsi, atau berbanding terbalik dengan logaritma cahaya yang ditransmisikan. Berdasarkan pengukuran spektrofotometri dapat dihitung konsentrasi sampel yang dianalisis. Alasan menggunakan metode analisis spektrofotometri UV-Vis adalah karena senyawa rhodamin B memiliki gugus kromofor yaitu gugus dalam senyawa organik yang mampu menyerap sinar ultraviolet dan sinar tampak seperti gugus karboksil, senyawa aromatik dan juga memiliki gugus auksokrom yaitu gugus yang memiliki pasangan elektron bebas seperti NR2. Hal pertama yang dilakukan adalah pembuatan larutan baku. Larutan baku, dibuat pada konsentrasi 1000 ppm dengan pelarut air dan menghasilkan larutan baku 1000 ppm yang berwarna pink pekat. Larutan baku tersebut kemudian diencerkan pada konsentrasi $0.1 ; 0.2 ; 0.3 ; 0.4 ; 0.5$ dan 0.6 ppm agar dapat diukur dengan spektrofotometer Uv-Vis sebab sampel yang terlalu pekat kemungkinan tidak akan terbaca sehingga perlu pengenceran. Variasi pengenceran (konsentrasi) digunakan untuk membuat kurva standar[5].

Selanjutnya di buat larutan sampel dengan cara mengekstrak rhodamin B pada sampel mie lidi. Rhodamin B pada mie lidi $10 \mathrm{~g}$ diekstrak dengan cara melarutkan sampel dengan larutan $2 \%$ amonia dalam $70 \%$ sebanyak $100 \mathrm{~mL}$. Waktu pelarutan sama dengan analisa kualitatif yaitu 1 malam. Rhodamin B yang telah terekstrak kemudian dipanaskan dengan tujuan 
pemekatan dan menguapkan pelarut. Selajutnya ditambahkan $10 \% \mathrm{NaOH}$. Hal ini bertujuan untuk mengubah kepolaran dari rhodamin $\mathrm{B}$ dengan melepas gugus $\mathrm{Cl}$ - pada senyawa sehingga struktur garam rhodamin dapat dipertahankan saat proses ekstraksi berlangsung. Kemudian ditambahkan air sebagai fase polarnya[12].

Ekstraksi dilakukan dengan larutan diklorometana. Prinsip ekstrasi ini ialah "like disolve like". Diklorometana disini berifat non polar sehingga dapat mengikat garam rhodamin B yang bersifat non polar. Air ditambahkan sebagai fase polarnya dan menghasilkan 2 fase karena perbedaan kepolaran, dimana fase atas berupa air dengan warna merah terang, dan fase bawah merupakan fase organik yang mengandung rhodamin B. Fase organik berada di fase bawah karena memiliki massa jenis yang lebih tinggi dibandingkan dengan air. Fase yang diambil adalah fase bawah. Larutan yang didapat diekstrak dengan $\mathrm{HCl} 0,1 \mathrm{~N}$. $\mathrm{HCl}$ disini akan mengembalikan rhodamin B pada fase polarnya sehingga terlepas dari fase diklorometana. $\mathrm{HCl}$ dapat mengembalikan kepolaran rhodamin B karena adanya gugus $\mathrm{Cl}-$, sehingga rhodamin $\mathrm{B}$ kembali pada struktur aslinya yang bersifat polar. Rhodamin B akan terikut pada fase asamnya. Fase asam berada pada fase atas karena memiliki massa jenis yang lebih rendah dibandingkan dengan diklorometana yakni $1,19 \mathrm{~g} / \mathrm{mL}$ banding $1,32 \mathrm{~g} / \mathrm{mL}$. Seharusnya fase asam berwarna merah, yang menunjukkan positif adanya rhodamin B. Namun, larutan yang diperoleh tidak berwarna. Seharusnya rhodamin B merupakan larutan berwarna karena menurut literatur yang ada panjang gelombang serapannya rhodamin B berada pada daerah visibel bukan daerah ultraviolet. Hal ini juga terlihat dari hasil scanning larutan standar yang menunjukkan panjang gelombang maksimum pada $555 \mathrm{~nm}$ (daerah visible)[6].

Panjang gelombang maksimum yang diperoleh pada scznning sudah sesuai dengan literatur yang menyatakan bahwa panjang gelombang maksimum rhodamin B berada pada daerah $554 \mathrm{~nm}$. Larutan yang tidak berwarna sebenarnya dapat dijadikan indikator bahwa larutan tersebut tidak mengandung rhodamin B. Namun, pengukuran absorbansi tetap dilakukan pada ekstrak sampel karena pada uji kualitatif sampel positif mengandung rhodamin B. Kurva standar rhodamin B dibuat pada panjang gelombang $554 \mathrm{~nm}$. Kurva standar yang dihasilkan adalah sebagai berikut:

Tabel 3.Perhitungan Kadar Rhodamin B

$\begin{array}{lc}\mathbf{y} & =\mathbf{b x}+\mathbf{a} \\ \mathbf{0 , 1 7 5} & =\mathbf{0 , 9 9 8} \mathrm{X}+\mathbf{0 , 3 5 9 6} \\ \mathbf{0 , 1 7 5 - 0 , 3 5 9 6} & =\mathbf{0 , 9 9 8 X} \\ -\mathbf{0 , 1 8 4 6} & =\mathbf{0 , 9 9 8 X} \\ -\mathbf{0 , 1 8 4 0} & =\mathbf{X}\end{array}$

Hasil perhitungan persamaan regresi kurva kalibrasi di atas diperoleh persamaan garis $\mathrm{y}=$ $0,0325+0,3721$ dengan koefisien korelasi sebesar 0,9986 . Hasil kolerasi yang terdapat positif antara kadar dan serapan, artinya dengan meningkatnya konsentrasi maka absorbansi juga aka meningkat[13].

Ekstrak sampel yang diperoleh absorbansinya diukur pada panjang gelombang maksimum rhodamin B pada daerah visibel yaitu $555 \mathrm{~nm}$. Nilai absorbansi yang diperoleh sebesar 0,175. Berdasarkan nilai absorbansi yang diperoleh dapat diketahui bahwa konsentrasi sampel sebesar $-0,1840 \mathrm{ppm}$. Hal ini menunjukkan bahwa terdapat rhodamin B dalam sampel yang kuantitasnya sangat kecil hingga hasil dari perhitungan kadar menunjukkan nilai minus (-). Hal ini dikarenakan ekstrak sampel yang diperoleh memiliki kepekatan yang sangat rendah sehingga nilai absorbansinya (y) lebih kecil dari nilai konstanta (a)[14].

Nilai R2 yang mendekati 1 menunjukkan bahwa data yang diperoleh semakin akurat dan praktikan dalam melakukan penelitian lebih teliti. Maka dari grafik diperoleh persamaan regresi liniar yang bias digunakan untuk mengukur konsentrasi larutan, tetapi tidak bias dijadikan 
patokan karena hasil yang didapat konsentrsi negative menunjukkan bahwa konsentrasi sampel $<0[9]$.

\section{Kesimpulan}

Berdasarkan penelitian yang telah dilakukan dari ke tiga sampel mie lidi yang di teliti, terdapat satu sampel yang positif mengandung pewarna rhodamin B dengan kadar atau konsentrasi yang sangat kecil.

\section{DAFTAR PUSTAKA}

[1] Cahyadi, "W. Analisis dan Asoek Kesehatan Bahan Pangan". 2009. Jakarta: PT. Bumi Aksara.

[2] Adnan, M., "Teknik Kromatografi untuk Analisis Bahan Makanan”, Edisi Pertama, 9, 14, 15, Penerbit Andi, 1997. Yogyakarta.

[3] Anonim, "Farmakope Indonesia Edisi V”. Departemen Kesehatan Republik Indonesia, 2014. Jakarta.

[4] Christian, Gary D., “Analytical Chemistry, edisi ke-5”. John Wiley \& Sons Inc.. 1994. New York.

[5] Djalil, A. D., Hartanti, D., Rahayu, W. S., Prihatin, R., dan Hidayah, N., "Identifikasi Zat Warna Kuning Metanil (Metanil Yellow) dengan Metode Kromatografi Lapis Tipis (KLT) pada Berbagai Komposisi Larutan Pengembang”, Jurnal Farmasi Indonesia, 03 (2), 2829, Fakultas Farmasi UMP, 2005. Purwokerto.

[6] Hidayat, R. "Laporan Pengantar tugas akhir perancangan buku pewarna alami dan buatan pada makanan”. Skripsi. Universitasi Komputer Indonesia. 2014. Bandung.

[7] Mulja, M., Suharman, "Analisis Instrumen, Cetakan 1, 26-32, Airlangga University Press, 1995, Surabaya.

[8] Putra FT., "Analisis kadar plumbum $(\mathrm{Pb})$ pada minyak goreng yang digunakan pedagang gorengan di sekitar jalan perintis kemerdekaan kota padang tahun 2015”. Skripsi. Fakultas Kedokteran Universitas Andalas. 2015. Padang.

[9] Rahayu., Muji. Wahyuningsih., Aisya. "Identifikasi Zat Pewarna Rhodamin B Dan Methanil Yellow Dalam Geplak Yang Beredar Di Beberapa Toko Oleh Oleh Di Yogyakarta Tahun 2016”. Jurnal Teknologi Laboratorium 05 (01). Yogyakarta : Poltekkes Kemenkes, 2016. Yogyakarta.

[10] Sastrohamidjojo, H., "Kromatografi", Edisi Kedua, 28, 34, Penerbit Liberty, 1991. Yogyakarta.

[11] Siswoyo dan Asnawati. "Analisis Spektrometri”. Jember : Laboratorium Kimia Analitik Jurusan Kimia Universitas. 2007. Jember.

[12] Stahl, E., "Analisis Obat Secara kromatografi dan Mikroskopi, diterjemahkan oleh Kosasih Padmawinata dan Iwang Soediro", 3-17, ITB, 1985. Bandung.

[13] Sumarlin, La Ode., "Identifikasi Pewarna Sintetis pada Produk Pangan yang Beredar di Jakarta dan Ciputat”. 2010. Jurnal Valensi, 1 (6) 55-62.

[14] Underwood, A. L. dan Day, R. A., “Analisis Kimia Kuantitatif”. 1999. Jakarta : Erlangga. 
